\title{
RESTORATIVE PRACTICES IN
}

\section{ACTION:}

\section{Tallaght West Childhood \\ Development Initiatives' \\ Restorative Practices Programme}

\section{Claire Casey}

\section{Abstract}

This article describes CDI's Restorative Practices (RP) programme in Tallaght West by discussing the origins, implementation and independent evaluation of the programme. A definition and explanation of RP based on existing literature and research is offered and the findings of the evaluation of CDI's RP programme are presented along with testimonies from users of RP in Tallaght West. CDI was one of three Prevention and Early Intervention Programme sites and is now funded under the Government's Area Based Childhood Programme which supports the delivery of a range of services to improve outcomes for children and young people in Tallaght. The article concludes with the key learning to date about the use and impact of $\mathrm{RP}$ in a community setting along with a discussion of possible areas for further research, or investigation.

\section{Keywords}

Restorative practices, childhood, development initiatives

\section{Restorative Practices in Action:}

\section{Childhood Development Initiatives' Restorative Practices Programme}

\section{Introduction}

This article aims to share learning about the use of Restorative Practices in an Irish community that is designated disadvantaged (Haase and Pratschke, 2012). It will begin by offering a definition of Restorative Practices and an outline of relevant research in this area. It will go on to describe the origins and content of the Restorative Practices Programme implemented by the Childhood Development Initiative (CDI) in Tallaght West since 2010; and to share some of the findings of the independent evaluation carried out by the Child and Family Research Centre at the National University of Ireland, Galway, between 2011 and 
2012. Examples of how restorative practices have contributed to building relationships and to preventing and resolving conflict in a community setting are then presented. The article concludes with some of the main learning by stakeholders to the Tallaght West Restorative Practices Programme and an outline of further areas for investigation or research.

\section{Context}

The aim of restorative practices is to develop community and to manage conflict and tensions by building relationships and repairing harm (IIRP UK, 2011). The International Institute for Restorative Practices (http://www.iirp.edu/) defines Restorative Practices (RP) as 'a social science that studies how to build social capital and achieve social discipline through participatory learning and decision-making' (Watchel, 2012). RP has its roots in restorative justice principles and practices (Shaw, 2007) which in turn originated in the criminal justice arena, based on a belief that crime is a violation of people and interpersonal relationships (Zehr and Mika, 1997). Such violation harms the victim, offender and others, and therefore creates problems that need to be addressed and resolved (Ibid).

However, while restorative justice deals mostly with providing an effective response to crime or wrongdoing, RP also draws on the principles and practices of family group conferencing, mediation and traditional healing circles to include preventative practices that aim to consciously build positive relationships and a sense of community (Watchel, 2012). Thus, RP places a strong emphasis on having a relational approach to problem solving: Drewery et al (2010) highlight that RP is not only aimed at resolving conflict but 'is about maintaining the basic values of a diverse and civil society, including generosity, care, and respect for difference'. Other key aspects of RP include an emphasis on the importance of dialogue and fair process, demonstrating and maintaining respect for each other, and developing social collaboration and supports (Macready, 2009).

As such, RP can challenge deeply held beliefs about how best to approach or respond to wrongdoing or harm, causing discomfort for professionals and practitioners used to more traditional approaches to discipline and authority (Blood \& Thorsborne, 2005). A shift in thinking and practice with regard to adopting a restorative approach is difficult to achieve, as it requires cultural change.

Most studies on the effectiveness of RP in reducing problem behaviours and improving outcomes come from schools where RP have been deeply embedded and fully integrated into school policy. Schools offer an opportunity to fully integrate a restorative approach at all levels and are particularly successful when strong leadership is in place (Drewery et al., 2010). Along with strong leadership, the successful adoption of RP throughout an organisation, such as a school, requires gaining commitment from key stakeholders in an organisation, developing a shared vision, developing effective restorative mechanisms and systems, ensuring a whole-organisational approach, and building positive, professional relationships (Ibid). Schools that have adopted restorative techniques have been shown to improve the attitudes of students towards learning, boost their morale, encourage them to take responsibility for their actions, improve relationships between teachers and students, enhance school culture, and improve pupils' grades (Wearmouth et al., 2007; Gellin, 2011). 
Research from Hull (Mirsky, 2009; Carlile, 2008) has demonstrated a wide range of benefits arising from the integration of restorative practice across professional disciplines and sectors.

These have included:

1. Increased stability in foster care placements and residential care;

2. Increased resolution of community disputes and reduction in disorder at community level;

3. Improved attendance and morale among staff and personnel of services dealing with children and young people;

4. Improved school attendance (primary and secondary);

5. Improved school attainment (primary and secondary);

6. Improved behaviour and attitudes among students (primary and secondary);

7. Reduction in the number of young people categorised as NEET (Not in Education, Employment or Training); and

8. Improved attendance and morale among teachers and school staff (primary and secondary).

Another exception to the predominance of school studies is found in the evaluation of a community RP programme run in Dún Laoghaire/Rathdown (Wilson, 2011). In this formative evaluation, Wilson (2011) found beneficial effects of training strategies implemented by the programme which included a number of staff in various organisations engaging well with restorative practices and concepts. The programme was found to be positive in giving people a voice and encouraging greater inter-agency working (Ibid). Given the scarcity of research on the use or impact of RP in non-school settings, findings from an independent evaluation of the CDI RP programme (Fives et al., 2013) will be highlighted following a description of the origins of the RP programme and its implementation over its first three years.

\section{Background to the Tallaght West Restorative Practices Programme}

CDI is funded under the Government's Area Based Childhood Programme (ABC), which builds on the learning to date from prevention and early intervention programmes. The $\mathrm{ABC}$ aims to break the cycle of child poverty in areas where it is most deeply entrenched and to improve the outcomes for children and young people where these are currently significantly poorer than they are for children and young people living elsewhere in the State (Department of Children and Youth Affairs, 2013).

CDI is based in Tallaght West and is the result of the professionalism, passion and persistence of a consortium of 23 concerned individuals and organisations in the community, who had a vision of a better place for children. Through innovative partnerships, they brought together the science of evidenced-based practice and rigorous evaluation, with the spirit of an approach focused on the identified needs of children and families. CDI was funded from 2007 to 2012 through a partnership between the Department of Children and Youth Affairs (DCYA) and The Atlantic Philanthropies (AP), under the Prevention and Early Intervention Programme, which was set up to support "innovative methods for improving outcomes for 
children in an integrated way" (DCYA, 2013). The ABC Initiative offers an opportunity to integrate proven models of practice.

CDI designed, delivered and evaluated a suite of programmes across a spectrum of local needs on language, literacy, health, early years, conflict management and community safety. All of CDI programmes are evidence-informed and manualised, and are delivered through existing structures and services.

The Community Safety Initiative (CSI) was developed as part of CDI's overall strategy to improve outcomes for children and families in Tallaght West. The need for an initiative aimed at improving community safety was identified in research and consultation conducted by the Dartington Social Research Unit (CDI, 2004) which found that safety in the community, particularly in relation to children's safety, was a shared concern among residents. Consequently, this became a key focus of the CDI strategy, with the Community Safety Initiative adopting a new approach to building and enhancing a sense of belonging to the community. Residents, the Gardaí, the local authority and other stakeholders worked on developing and implementing activities to identify and address the most common factors that negatively impacted on the community's experience of safety. Restorative Practices became a key element of this approach.

CDI's Community Safety Initiative got underway in 2006 with a comprehensive consultation and research process with the community and key stakeholders about how safety in the community could be improved. The process included consultations with, and surveys of, community groups, service providers, residents, young people and children. The report (Cahill, Guerin, \& Murphy, 2008) highlighted three key action themes for the CSI to focus on: young people (including facilities, services and pro-social activities); physical environment; and community engagement. Work began in 2008 to engage with residents in a number of small pilot sites (approximately 100 households each) about priority safety needs in their neighbourhood. Over the next two years, various activities were undertaken on pilot sites and in Tallaght West generally to develop community engagement with the CSI, to build relationships between residents and service providers and to address a number of safety issues identified through local surveys. Examples of community engagement activities included community clean-ups, Family Fun Days, Children's Good Behaviour Awards, football tournaments, and volley ball leagues, as well as a comprehensive programme of training and capacity building with residents and those working with them. In 2010, CDI identified the RP work of the Hull Centre for Restorative Practices (www.hullcentreforrestorativepractice.co.uk) as being relevant to the Tallaght West context, and offering a model which could meet locally identified needs.

An approach which supports everyone to build healthy relationships, to look at where we are accountable, and to take responsibility for our actions was an appropriate fit with the dynamics and relationships within Tallaght West, and the solution-focused model offered an outcome based and sustainable intervention. Evidence from Hull demonstrates that a range of organisations had taken on a restorative approach to their work, and achieved positive results in very short time frames.

For example, after only one year, the nine schools where restorative practices were initially piloted reported the following: 
$79 \%$ reduction in class disruption; $92 \%$ reduction in exclusions from breaks;

$81 \%$ reduction in days lost from fixed term exclusions; $79 \%$ reduction in reported verbal abuse to staff; $80 \%$ reduction in pupil to pupil physical abuse; $82 \%$ reduction in incidents at lunch;

and a 92\% reduction in reports to the Principal or other senior staff (Irish Youth Justice Service, 2010).

CDI recognised RP as an approach with the potential to greatly assist the work of the CSI by equipping people with a set of highly effective skills for building strong relationships and resolving conflict in a healthy manner. It was agreed by the CSI Steering Committee to develop a Restorative Practice Programme of training and support which would support Tallaght West to become a restorative community. A series of meetings were held with the CDI team and key stakeholders (including members of the Local Authority, Gardaí, Youth Service, Health Service Executive, Schools, Community Organisations and Residents) to promote the concepts of RP and achieve buy-in to the idea of working to develop a restorative community. There was a particular focus on engaging Senior Managers early on, and identifying champions to promote the approach.

\section{Overview of the RP Programme in Tallaght West}

The RP Programme in Tallaght West got underway in 2010 when an RP Programme Management Committee was established to oversee the roll out of training, the development of supports and the independent evaluation of the work.

The anticipated outcomes of the RP Programme were:

Improved collaboration between agencies and groups working with children and young people; Improved relationships between residents and the providers of services to children and young people; Increased use of a common language among services providers from different agencies;

Increased satisfactory resolution of neighbourhood disputes in Community Safety Initiative (CSI) Pilot Sites;

Reduced anti-social behaviour and crime in CSI Pilot Sites; Improved pupil attendance within participating schools;

Reduced disciplinary issues within participating schools; and Improved staff morale within participating schools.

Training was delivered by the UK Office of the International Institute for Restorative Practices (http://uk.iirp.edu) on a monthly basis and targeted all of the agencies with responsibility for children and young people (including schools, early year's services, youth services, educational welfare staff, local authority staff, probation services, community centres, community Gardaí, adult education services, etc.) as well as parents and young people themselves. Between July 2010 and September 2013, 971 people from Tallaght West and other communities received training (including 109 young people, i.e. aged 14 to 20 
years) and 14 people living or working in TW were accredited as RP trainers as part of building capacity to sustain the programme in Tallaght and to develop RP approaches in Ireland as a whole.

In keeping with its' commitment to being evidence-informed and to identifying 'what works' in order to influence policy and practice, CDI commissioned the Child and Family Research Centre (www.childandfamilyresearch.ie) at the National University of Ireland, Galway, to undertake an independent evaluation of the RP Programme (Fives et al., 2013). The research, which employed both quantitative and qualitative methodologies, was carried out between 2011 and 2012. The evaluation report was published in May 2013.

The findings of this report contribute an Irish perspective to the international research on the implementation of, and outcomes arising from, RP in a community setting and indicate that the training has been of benefit in a number of ways to those who have participated:

$87 \%$ of trainees reported being better able to deal with conflict as a result of taking a restorative approach; Trainees reported a 43\% reduction in disputes in the workplace, home and community; Trainees reported that RP had helped to significantly improve relationships with users of their services (up 61\%), their work colleagues (up 47\%) and their family members (up 47\%); and, to a lesser extent, RP was found to help improve relationships with neighbours (up 14\%) (Fives et al., 2013). The researchers also found that the RP Programme had contributed to improved collaboration between agencies and organisations, and that the programme had positive impacts in a range of work settings and at home (Fives et al., 2013).

\section{Examples of RP in Action}

The following are examples of the how restorative practices have been used by people in Tallaght West, as reported to CDI between 2010 and 2013. These examples are collected from people who have undergone RP training with CDI; trainees were asked to provide CDI with a written account of verbally reported use of RP, which CDI can use for training or promotion purposes. The examples are, therefore, self-reported accounts of the use and impact of RP and are chosen to reflect the range of settings in which $\mathrm{RP}$ is being implemented in the community and each example is a verbatim statement from a member of the community who has been anonymised.

\section{RP used in the Home}

"My teenage daughter arrived home with her school report, which wasn't great. My instincts were to defend, argue. Her body language was defensive, and she was monosyllabic. But eventually we got to the point in the conversation where we really began to talk, listen, understand. There were plenty of tears. RP helped me to really listen to and understand her. It gave me an empathy that was missing previously. I needed to leave my own emotions out of it. It allowed both of us to offload something. The restorative training helped me to ask the right questions, and to step out of thinking of her as my daughter and instead to really listen to what she was saying. You have to put in the time to make it work. We would never have got there in a five-minute chat" (2011). 
"A family dispute has been going on for a year now. I used RP in an attempt to resolve the issue. Asking the core questions helped. Stepping back, removing myself was key. I stopped being part of the problem by removing my own feelings from the discussion. People having the opportunity to be heard was what made the difference. Although it is not completely resolved it is now well on the way to recovery" (2010).

\section{RP in a Work Setting}

"I manage a centre in Tallaght and am responsible for a number of staff members. On occasion I have been aware certain staff members were not getting on but I did not get involved and hoped it would work itself out. Following the restorative practice training I decided to try the process out with the staff. It was obvious something was erupting as the tension in the air was quite apparent. I was nervous but I prepared myself by rehearsing the questions provided in the training. The staff were gathered in a circle and each member was given the opportunity to say how they felt about the situation. Everyone felt truly respected and listened to. The process allowed me not to become involved and on occasion the focus wandered and I had to remind them of the purpose of the gathering. Overall it was a great experience and all staff members were happy at the end. Using the script really works and is very useful." (2011).

\section{RP in Schools}

"A parent came to the school recently to tell us that her son was afraid to come to school. At home, both she and her son were experiencing intimidation, verbal abuse and verbal threats from a local group of young people. The group were involved in a feud with her son and his friends. The group "leader" is also a student at our school. She was looking for school support in resolving the issue. We told her about restorative practices. We offered to bring her son and the other young person together to help resolve the issues causing the conflict. Preparation was the key to a successful outcome. Both agreed to a restorative circle, once I explained what would happen. It was easy for them to agree to the circle because they knew what would happen, and what questions would be asked. A restorative circle took place between the two students, I and a colleague. The leader of the group involved in the intimidation showed great empathy for the thoughts of the other student. As part of "what needs to happen next", the student leading the group agreed to speak with his friends and ask them to end the feud and the intimidation. It has been three weeks now since the restorative circle. All is well." (2011).

"Thank you so much for the training, it is the best training I have ever done. I am the School Guidance Counsellor and deal with a lot of discipline issues, mostly related to bullying. I have been using the restorative questions since the training a month ago and it has made a huge difference. I have already had two different parents contacting me to thank me for helping to stop the bullying of their child. The Principal here is really impressed and wants everyone to do the training now." (2013). 


\section{RP in Youth Work Settings}

"There was a young person disrupting the session, and one of the staff took him aside and very quickly asked key questions which enabled him to see his behaviour as others saw it. He decided to take time out, following a three-minute check in using the RP questions card. He told one of the staff he felt listened to. Staff have been using the skills and feeling empowered," (2012).

"I was facilitating a summer programme and two of the young people got into an argument as we were getting onto the bus, and one of them made some racist comments to the other. My colleague and I separated them on the short bus journey but asked to speak to them when we returned. We facilitated a small impromptu restorative conference, one of the young people was the 'wrongdoer', the other and my colleague were 'harmed persons' (my colleague had witnessed the argument). The young people had no experience of Restorative Practice or Conferencing before, but engaged readily in the process. The outcome wasn't as positive as I had hoped, but the young people apologised to each other, shook hands and agreed to stay away from each other at the beach BBQ the following day. At the beach BBQ, however, I witnessed the 'wrongdoer' sharing his burger with the 'harmed person'," (2012).

"Restorative approaches were used to manage disruptive behaviour in a youth group and the outcome was that the group became self-regulating, managing their own ground rules and taking responsibility for how they participated. They got to say how they felt and also to hear how it was for the staff. A lot of the time, discussions are just about the behaviour and not about what underpins the behaviour. It was also really important that the process allowed the young people to hear and understand the experience of the staff," (2011).

\section{RP in the Community}

"I heard about RP from my neighbour when I asked her how she had sorted out a problem she had been having. There was a group of teens hanging around on her front garden wall consistently causing a disturbance and her husband had been going out all guns blazing trying to get them to move away but they kept returning. Then one day my neighbour went out and, even though she was incredibly nervous, she approached the youths and calmly explained that there was a baby in the house and she was trying to get him to sleep in the front room but with all the messing going on outside she couldn't manage it. The teens immediately changed their attitudes and once they could see the pressure and, more importantly understand the pressure the woman was under, they apologised and moved off.

They haven't returned since and I want to do the RP training now," (2013).

\section{Conclusion}

CDI began its RP Programme with an overall vision of equipping those working or interacting with children and young people with the skills to build strong relationships and to effectively and easily support the resolution of conflict when it arises. The independent evaluation, CDI's experience and that of a plethora of people working with or concerned about young people, confirm that consistent use of a 
restorative approach will do both of these things and more.

CDI have observed that young people have taken to RP with enthusiasm and are some of the strongest advocates for its use across the community. CDI have also observed that RP helps strengthen all relationships, and has been of particular use to service providers in both managing their relationships with service users (young people and adults) and in more effectively managing conflict within the workplace. The skills and approach encompassed by RP appear to be readily transferable and, once they become an integral element of practice and part of the organisational culture, they appear to filter through to all relationships and types of engagement.

Alongside the learning from this and other evaluations, there remain critical questions yet to be explored. In particular, it would be very helpful to empirically test whether RP $\underline{\text { does }}$ contribute to reducing bullying among teenagers (as CDI have heard numerous times since 2010); and to examine whether RP is a more effective mechanism for equipping young people with personal development skills and confidence than other strategies currently in use by schools and youth organisations.

CDI's vision for a restorative community has progressed significantly in a short timeframe, but there is considerable work remaining to ensure that the approach is embedded across all disciplines and organisations; that it becomes integral to how we engage with each other, and that it provides a consistent mechanism through which we minimise and manage conflict. The fundamental question remains however: is a restorative community one in which children and families achieve better outcomes? We know that instinct is not an adequate indicator, and hope to continue to monitor and assess impact 


\section{References}

Blood, P. \& Thorsborne, M. (2005) The Challenge of Culture Change: Embedding Restorative Practice in Schools. Paper presented at the Sixth International Conference on Conferencing, Circles and other Restorative Practices: "Building a Global Alliance for Restorative Practices and Family Empowerment”. Sydney, Australia, March 3-5.

Cahill, J., Guerin, S. \& Murphy, T. (2008) Community Safety Initiative: Consultation Report. Dublin: Childhood Development Initiative.

Carlile, P., (2008) The City of Hull: Riverside Project. Hull: Hull Centre for Restorative Practices and IIRPUK. CDI (2004) How are Our Kids? Children and Families in Tallaght West, Co. Dublin. Dublin: Childhood Development Initiative.

CDI (2005) A Place for Children: Tallaght West. Dublin: Childhood Development Initiative.

Department of Children and Youth Affairs, (2013) Area Based Response to Child Poverty Initiative 2013

- 2016 [online], DYCA, accessed from www.dcya.gov.ie/documents/PreventionAndEarlyIntervention/Child_Poverty_Seminar_25042013_M.O M.pdf [7th November 2013]

Drewery, W. \& Kecskemeti, M. (2010) Restorative practice and behaviour management in schools: discipline meets care. Waikato Journal of Education, 15(3), 101-113.

Fives, A., Keenaghan, C., Canavan, J., Moran L., \& Coen, L. (forthcoming, 2013) Evaluation of the Childhood Development Initiative's Restorative Practice Programme. Dublin: Childhood Development Initiative (CDI).

Gellin, M. (2011) “Even a child can mediate". What kind of learning are restorative practices in schools producing? - An article on survey results' Accessed via:

www.ssf-

ffm.com/vertaissovittelu/assets/files/Learning\%20in\%20mediation\%20MGELLIN\%202011.pdf

Haase, T., \& Pratschke, J. (2012). The Pobal HP Deprivation Index [online], Pobal, accessed via: www.pobal.ie/Pages/New-Measures.aspx [accessed 7th November 2013]

International Institute for Restorative Practices, UK (2011) Introduction to Restorative Practices: Training Script. UK: International Institute for Restorative Practices, UK.

Irish Youth Justice Service (2010) Young People and Crime - Where to Now? Conference Report. Dublin: Irish Youth Justice Service.

Macready, T. (2009) Learning social responsibility in schools: a restorative practice. Educational Psychology in Practice, 25(3), 211-220.

McCluskey, G., Lloyd, G., Kane, J., Riddell, S., Stead, J., \& Weedon, E. (2008). Can restorative practices in schools make a difference? Educational Review, 60(4), 405-417.

Mirsky, L. (2009) Hull, UK: Toward a Restorative City. Restorative Practices E-Forum, International Institute for Restorative Practice. Accessed via: www.iirp.edu/pdf/Hull.pdf.

Prevention and Early Intervention Programme for Children (2013) Department of Children and Youth Affairs, [online] accessed from

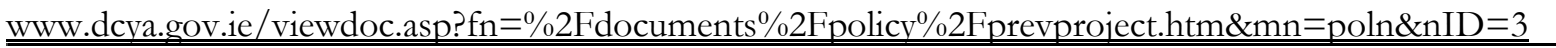


$\left[7^{\text {th }}\right.$ November 2013]

Shaw, G. (2007). Restorative practices in Australian schools: Changing relationships, changing culture. Conflict Resolution Quarterly, 25(1), 127-135.

Wachtel, Ted. (2013) "Defining Restorative. International Institute for Restorative Practices. Retrieved $26^{\text {th }}$ March, 2013.

Wearmouth, J.; R. Mckinney and T. Glynn (2007) Restorative justice in schools: a New Zealand example. Educational Research 49(1): 37-49

Wilson, D. (2011) Dún Laoghaire / Rathdown Comenius Regio 'Restorative Approaches' Programme 2010-2011: A Formative Evaluation. Belfast: University of Ulster.

Zehr, H., and Mika, H. (1997) Fundamental Concepts of Restorative Justice. Contemporary Justice Review: Issues in Criminal, Social and Restorative Justice, 1(1), 47-56.

Claire Casey is Community Engagement Coordinator with the Childhood Development Initiative (CDI) in Tallaght West. Her role includes implementing CDI's Community Safety Initiative which developed a Restorative Practice Programme as a core strategy in promoting stronger relationships and community safety. Claire has worked in Community Development for over 20 years in both a voluntary and paid capacity in a range of anti-poverty projects based in disadvantaged communities in Dublin where she has focused on supporting communities to develop and implement their own solutions to the issues that they struggle with. 